João Carlos Tedesco

Universidade de Passo Fundo

\title{
Casamentos mistos: novas sociabilidades e quadros coletivos. Aspectos da imigração de brasileiras na ltália
}

\begin{abstract}
Resumo: O texto analisa aspectos da imigração de brasileiras para a ltália dando ênfase para as uniões conjugais com italianos; localiza o horizonte do trabalho no interior das famílias italianas como um cenário que viabiliza essa possibilidade e demonstra que os casamentos mistos revelam múltiplos horizontes subjetivos, preconceitos, redes de sociabilidades étnicas, integrações transfronteiriças e reconfigurações de famílias.
\end{abstract}

Palavras-chave: imigração; casamentos mistos; gênero.

Copyright () 2014 by Revista Estudos Feministas.

' Tereza Kleba LISBOA, 2006.

2 CARITAS/MIGRANTES, 2012.

\section{Consideraçōes iniciais}

As discussões sobre imigração de mulheres estão sempre presentes nos estudos sobre migrações internacionais. Historicamente se fez presente a ideia de que primeiro migram os homens, depois as mulheres, ou que a imigração é "coisa de homem". Na realidade, essas representações, ainda que possam estar presentes e mobilizar narrativas, tendem a não ser mais tão expressivas da prática migratória contemporânea; além da esfera da mobilidade espacial, há o horizonte do trabalho que, em geral, também revela processos que caracterizam relações de gênero.

Para a nossa realidade de análise específica, os dados demonstram que aumentou muito o número de mulheres que migraram nos últimos anos para a ltália. ${ }^{1} \mathrm{Em}$ 2000 , o índice atingiu $46 \%$ do total global dos imigrantes. Em 2008, subiu para 49,9\% e, em 2010, já ultrapassou a metade dos fluxos (53\%). Para o caso da imigração brasileira, esse índice é bem mais alto, atingindo, em 2011, $74 \%$ do total de imigrantes. ${ }^{2}$ 
${ }^{3}$ FONDAZIONE ISMU, 2011

${ }^{4}$ Francesca DECIMO, 2005.
Em geral, há uma ligação entre imigração de mulheres com o universo da família. Essa tem um papel chave no processo migratório, assim como este também o tem sobre a família, principalmente no que tange às redefinições de obrigações, responsabilidades, solidariedades, papéis de gênero, de intergerações e no campo afetivo no local de destino.

Os dados da imigração na Itália demonstram que houve, nos últimos anos, um grande aumento do contingente de mulheres que migram e reagrupam maridos, ou que imprimem uma nova vida conjugal com autóctones ou com outros imigrantes. $^{3}$

Nesse sentido, com a emigração, redefinem-se relações, produzem-se novas dinâmicas relacionais, de integração e de formatos de família. Vimos casos de mulheres que emigraram em razão do divórcio, de infelicidade no casamento, de convites de familiares, amigas, vizinhas e parentes, das possibilidades de constituir novas conjugalidades etc.

Simplesmente eu disse pra ele, 'tô indo com a Lizelda' [sua prima]. [...]. Decidi de vir, ele [seu marido] não queria de nenhum jeito, disse que então era melhor separar, dai eu aproveitei pra dizer: 'pois então tava na hora agora disso', e aconteceu mesmo. [...], é triste, dói deixar meu filho de 13 anos. [...]. Lutei até que consegui, depois de quase três anos, trazer ele aqui. Tenho meu filho aqui agora junto e é pra ele tudo que faço. [...] meu divórcio saiu e casei de novo aqui na ltália com ele [italiano]. [...] realizei meus sonhos. (Imigrante, oriunda de Feira de Santana - BA, há cinco anos na Itália, e, no momento da entrevista, residia em Brescia)

Há uma vasta literatura que enfatiza causalidades e estratégias diferenciadas entre homens e mulheres no processo migratório, em geral, identificando a mulher como alguém que se move mais por motivações no campo afetivo e familiar; o econômico está presente, mas em menor medida. ${ }^{4}$ Outra constatação é que as mulheres sempre migraram no decorrer da História e continuam migrando hoje com grande intensidade. Algo que perdura nessa longa trajetória é a sua pouca visibilidade no cenário migratório; no caso italiano, muitas delas trabalham em casas de famílias e, em geral, são as maiores vítimas da informalidade e irregularidade no horizonte das relações de trabalho e de performance legal no país. Não é incomum a literatura sobre o tema enfatizar os préjuízos em torno disso, ou seja, os homens migram por causa do dinheiro, e as mulheres por "causa de sentimentos pessoais", 5 e se "enclausuram nas casas de família e de lá não saem". 6

Diz Assis ${ }^{7}$ que há elementos, no campo das identidades e representações sociais, em geral no campo da discriminação e subordinação, que determinados grupos e sociedades produzem em torno da mulher e, em especial, da 


\footnotetext{
9 Pesquisamos desde 2002 sobre a imigração brasileira para a ltália. Essa trajetória de pesquisa rendeu dois livros (cf. bibliografia final), um estágio de professor visitante na Universidade de Verona (20082009), bem como dois estágios de pós-doutoramento (em 2002, na Universidade de Verona, e em 2011, na Universidade de Milão). ${ }^{10}$ Adiles SAVOLDI, 1998.
}

"Adriana PISCITELLI, 2002; 2005 Ver também discussões em torno disso em Tadeus BLANCHETTE, 2011 . mulher trabalhadora. Os baixos salários no país de origem, somados às condições de subalternizadas em vários campos, e a necessidade de acompanhar a rede familiar que migrou, entre outros aspectos, fazem da emigração feminina uma dinâmica de forte intensidade e de pouco reconhecimento ou representação de identificação social.

Tendo presente esse quadro geral esboçado, daremos ênfase a uma realidade bastante evidente na ltália que são os denominados "casamentos mistos", no caso em questão, especificamente de mulheres brasileiras com homens italianos. É uma realidade que vem aumentando muito e chamando a atenção de analistas. Sempre que se fala de "brasileiras na ltália", tem-se o comentário e a produção da representação de seus vínculos conjugais com italianos. Os dados colocam o Brasil como uma das nacionalidades de maior expressão nesse sentido. ${ }^{8}$

Acompanhamos aspectos da realidade de sete casais (dois na Província de Milão, três em Brescia e dois em Verona), com a intenção de perceber suas trajetórias, dinâmicas da nova vida conjugal, enfrentamentos, redes de contato, perspectivas e alguns dos universos relacionais no espaço em que estão com o local de origem das imigrantes. Esses foram contatos pessoais mais aproximados, presentes em suas casas, em jantares com outros grupos de brasileiros etc. Fizemos entrevista contendo histórias de vida, identidade das imigrantes, processos que ocasionaram a união matrimonial, alterações e dinâmicas da vida atual etc. Outros contatos foram obtidos com ambos por e-mail e Facebook. Também entrevistamos outras imigrantes que haviam casado na ltália, porém, foram contatos aleatórios, conversas obtidas em meio a outras demandas de pesquisa, em particular, em torno da educação e de segundas gerações. ${ }^{9}$

Insistimos na ideia de que essas realidades afetivas são expressões de anéis que compõem as várias redes do processo migratório; revelam estratégias de imigrantes, os quais produzem contatos sociais com autóctones, servindo de pontes sociais e afetivas ${ }^{10}$ que transcendem as fronteiras dos países e se agrupam em interações de longa distância.

Nesse sentido, enfatizaremos que há redes que viabilizam processos afetivos, casamentos entre italianos/as com brasileiros/as, contatos que vão se viabilizando entre os dois países pela esfera do denominado "turismo sexual"11; há também imigrantes que adotam estratégias de "casamentos arranjados" (com autóctones ou entre conacionais) para viabilizar reconhecimento de cidadania, bem como alianças afetivas e efetivas, as quais vão se desenvolvendo, alimentadas por múltiplas intencionalidades. 


\section{Em direção à pátria-mãe}

A Itália é um dos países que sempre foi visto como de emigrantes; porém, nos últimos 20 anos, já incorporou outra identidade: um lócus de imigrantes; é um dos países em que essa dinâmica se tornou intensa em razão de processos econômicos, demográficos, geográficos, culturais, de legislação etc.; talvez seja um dos países que mais produziu polêmicas, siłuações que chamaram a atenção pública em torno do tema.

Em 2011, o país já alcançou a casa dos cinco milhões de imigrantes regulares, isso sem falar nos irregulares e ilegais que, acredita-se, ultrapassem a casa de meio milhão. ${ }^{12}$ Houve um aumento de três milhões no último decênio e de quase um milhão no último biênio, o que significa dizer que é um país com dinâmica migratória intensa e de uma forma abrupta.

Segundo dados de pesquisa da Caritas/Migrantes (de 2012), o Brasil possuía, em 2011 , aproximadamente 50 mil imigrantes (esse dado difere muito dos do ltamaraty, que estipula cerca de 85 mil, pois os dados na ltália não contabilizam os que já possuem a dupla-cidadania, por não demandarem regularização em suas repartições públicas que tratam disso, como o fazem os que não a possuem; desse contingente, $74 \%$ é composto por mulheres, e, das 189 nacionalidades presentes na ltália, o Brasil é a que possui o maior percentual de mulheres sobre o total de imigrantes.

As regiões de maior concentração de brasileiros são as mesmas da emigração em geral da ltália para o Brasil, ou seja, na Lombardia, com em torno de 14 mil; em Vêneto, com aproximadamente nove mil; no Piemonte, com quase sete mil;

${ }^{13}$ CARITAS/MIGRANTES, 2012, p. 189.

${ }^{14}$ Lili KAWAMURA, 2003. e no Lazio, com cerca de seis mil. ${ }^{13}$ A denominada "emigração de retorno" (aos descendentes) é expressão de uma identidade de "bons imigrantes"; em geral tende a ser auxiliada, beneficiada para retornar, pois são os considerados mais adaptados, os que, em teoria, terão melhor capacidade de assimilação do trabalho, da cultura italiana, etc. Como diz Kawamura, ${ }^{14}$ esses oriundi acabam sendo uma população que atende às necessidades raciais e ideológicas, de esfera política, das demandas do mercado de trabalho como força barata, não qualificada e, de certa forma, controlada etnicamente.

Tem-se muito a ideia na Itália de que brasileiros são amparados pela dupla-cidadania, que são todos oriundi, provenientes de um país emergente que possui relações históricas com a ltália em termos de imigração, por isso, os imigrantes circulariam mais facilmente no interior do país. No entanto, a realidade que evidenciamos empiricamente não é bem assim; há uma distância entre representação e realidade. Muitos imigrantes estão em condição irregular

118 Estudos Feministas, Florianópolis, 22(1): 115-133, janeiro-abril/2014 
15 Ver: João Carlos TEDESCO, 2012

${ }^{16}$ São acordos viabilizados entre cidades consideradas coirmãs entre o Brasil e a ltália, em razão de territórios e grupos migratórios identificados historicamente, que servem para promover intercâmbios culturais, imigração de brasileiros amparados por empresas, instituições religiosas e públicas, cursos profissionalizantes na ltália etc.

${ }^{17}$ Abdelhafid HAMMOUCHE, 2007. (vimos isso no caso da agricultura e no interior de famílias de autóctones); ${ }^{15}$ a grande maioria não possui a duplacidadania, aliás, os que a possuem nem figuram nas estatísticas como imigrantes, atuam em setores que são designados para "os de fora", independentes da duplacidadania e/ou de outras formas de imigração tutelada, portanto, incorporam e reproduzem as relações precárias no mundo do trabalho.

Os vínculos que ligam grupos regionais e territoriais considerados comuns, de irmandades histórico-culturais (como os gemellaggios) ${ }^{16}$ acionam canais que viabilizam migrações tuteladas, temporárias, mas que, com o tempo preestabelecido vencido, acabam produzindo imigrantes irregulares, bem como alimentando redes que viabilizam novas emigrações.

As segundas gerações de brasileiros já estão marcando presença nas escolas e em outros espaços sociais (segundo os dados da Caritas/Migrantes de 2012, já ultrapassam nove mil); são a expressão de novas redefinições na concepção de imigração, no campo cultural e societal. As segundas gerações tendem a revelar novas concepções e projetar novas identidades de imigrantes no interior da sociedade maior. Desse modo, entendemos que as mobilidades e os processos sociais e culturais vão se alterando em concomitância com a dinâmica das relações sociais e dos contextos nos quais elas ocorrem. ${ }^{17}$ Nesse horizonte móvel, reproduções variadas vão acontecendo, ou seja, espaço, tempo e as pessoas não se recompõem da mesma forma; alguns retornam, outros permanecem e produzem novos fluxos, um contingente significativo encontra formas de permanecer no país através de (re)constituições familiares e afetivas.

\section{Trabalho e novas sociabilidades}

Famílias se redefinem, tanto no espaço de saída quanto no de origem; condições específicas da realidade migratória produzem horizontes variados de relações e concepções de gênero.

Boa parte do cenário de trabalho das imigrantes brasileiras está representada pelo contexto familiar do país de destino. A imigração de brasileiras possui, em grande parte, essa referência. Esse processo se constitui em razão de fatores, os quais adentram para o campo cultural e étnico, passando pela dupla-cidadania, pelas redes e contatos formais e informais que vão se produzindo entre entidades italianas e brasileiras (principalmente os gemellaggios), entre regiões da Itália e do Sul do Brasil. ${ }^{18}$

Várias imigrantes interlocutoras disseram ser o trabalho em famílias algo transitório, "até encontrar algo melhor", fato 
esse que, na prática, não se evidencia tão facilmente. Quem trabalha em casas de famílias "acaba se acostumando, não tem tempo pra ver outra coisa. Quando vejo os custos de trabalhar fora com comida, roupa, e aluguel, ah!, daí repenso melhor"; é uma atividade que não requer e nem permite entrar em horizontes culturais mais amplos. Isso não significa dizer que não existam momentos que se traduzam em intercâmbios, sociabilidades e experiências culturais (no cotidiano da cozinha, por exemplo, ao assistir televisão, ao passear com idosos, ao dar ouvidos às suas histórias etc.).

Aprendi muita coisa, aprendi a ser sentimental aqui, a amar mais meus pais cuidando de um idoso aqui; aprendi várias coisas e o sentimento humano, a gentileza que tem de ter aqui, no pedir as coisas sempre agradecer, grazie e prego [obrigado e de nada] pra tudo; vi que a saudade que sinto dos meus no Brasil, a tristeza por estar longe, nem de perto alcança a tristeza e a depressão de idosos que dizem todos os dias "é meglio morir, mi sento morire" [é melhor morrer, me sinto morrendo], porque estão sozinhos, filhos se mandam pro trabalho, não têm quem fique junto. [...]. É engraçado porque penso que nós estamos aqui assim pelo dinheiro, por querer ganhar dinheiro, e eles estão assim porque têm dinheiro demais! (Brasileira, oriunda de Vitória - ES, há dois anos em Desenzano, província de Bréscia)

Segundo as entrevistadas, no interior das famílias aprende-se a língua italiana. "No início, não sabia nada, um português misturado com não sei o que, dava conta de me fazer entender. [...]. Com o tempo, fui aprendendo, nos trancos e barrancos". A mesma entrevistada diz que "quem trabalha em casa de família aprende logo". Falar italiano no interior das famílias é uma necessidade e habilidade para dialogar. O diálogo auxilia na separação das distâncias em múltiplos sentidos, ameniza a dimensão do sacrifício. A língua abre horizontes, inclusive para tentar algo que permita às imigrantes certa mobilidade social e contatos mais próximos com italianos.

Dos sete casamentos que analisamos, em três deles a relação afetiva se produziu pelo trabalho no interior das famílias.

Quando trabalhava lá eu era bem tratada, sentia que minha sogra estava me empurrando pra ele [risada do marido]; queria que eu casasse com ele. No fundo eu não entendia como é que a sogra queria uma brasileira na família, uma imigrante, tinha tantas italianas ricas! [...]. Acho que ela tinha medo que ele [marido] não iria mais desencalhar [risos]. [...]. Na verdade, ela aceitou depois que foi fazer uma visita na casa de meus pais, viu de certo que não era tão pé-rapado assim. [...].

120 Estudos Feministas, Florianópolis, 22(1): 115-133, janeiro-abril/2014 
19 Zigmunt BAUMAN, 2002.

${ }^{20}$ Francesca DECIMO e Giuseppe SCIORTINO, 2006.

${ }^{21}$ Francesco CARCHEDI; Giovanni MOTTURA; e Enrico PUGLIESE, 2003.
Temos dois filhos; tô super feliz, já temos investimentos no Brasil, mas eu quero criar meus filhos aqui, talvez, com eles criados e trabalhando, a gente vai viver a aposentadoria no Brasil; eu penso assim. (Imigrante, oriunda de Guarapuava - PR, casada com italiano há quase cinco anos)

O trabalho nas casas de família coloca face a face pessoas em dimensões cotidianas de existência (cuidar, comer, conversar, dormir, lavar, comprar, passear, visitar...), numa troca de fortes dimensões culturais, afetivas e psicológicas que vão também se expressar na cozinha, na limpeza, na vestimenta, na rua, nos cuidados à saúde, nos contatos com pessoas de seu interior e exterior; individualizações se exteriorizam mais facilmente por ser o espaço da casa, não da rua e nem da empresa. ${ }^{19}$

Ela se afeiçoou tanto que eu sempre me senti na família; mas nunca pensei em fazer parte dela. Foi muito difícil no início; eles, ele mais [o sogro]; meu marido tinha 49 anos na época [4 anos atrás] e eu 30. Isso também dificultou pra mim, minha mãe não queria nem saber, mas o dinheiro e a segurança pros filhos fizeram ela aceitar! [...]; eu vou fazer minha vida aqui, mas consigo mais vezes visitar meus pais, eles também vêm pra cá [...], já tão todos acostumados. (Imigrante brasileira, casada com italiano; há quase cinco anos na Itália)

Há uma multiplicidade de percursos que vão constituindo as interações com a sociedade, com os grupos familiares, bem como há ganhos, perdas e riscos quando é feita a tentativa de (re)construção de identidades distanciadas, de assimilações forçadas, de junções de tempos distantes, de horizontes biculturais. ${ }^{20}$

Em geral, o trabalho nas famílias, ligado às questões de gênero e de nacionalidade, revela ser uma realidade complexa, expressiva de uma densidade de sentimentos, contrastes, afetos, hábitos, responsabilidades, excitação e desejo de um lado; de outro, preocupações, medos, estranhamentos, racionalizações que alimentam a decisão de emigrar. As imigrantes vivem no interior das casas sempre num horizonte fronteiriço, ${ }^{21}$ são independentes, mas são "pessoas de casa"; são estranhas, mas o trabalho exige graus intensos de afetividade (com idosos e crianças); são trabalhadores remunerados, mas que se mesclam à vida familiar: "a gente se envolve cuidando dos outros", sentindo-se "uma da família".

Imigrantes, em geral mulheres, envolvem-se na intimidade e na divisão do espaço e dos objetos do cotidiano da casa do italiano. Em geral, no trabalho full-time, há uma convivência live-in, fato esse que acaba, por fim, num horizonte hierárquico, fazendo parte da família, de seus dilemas e problemas. 
${ }^{22}$ Utilizamos essa noção por ser usada nos materiais que fazem análises estatísticas sobre imigrantes na Itália, em particular, a Caritas/Migrantes em seu Dossiê anual sobre o tema da imigração. A mesma serve para caracterizar a união conjugal entre imigrantes e nativos de ambos os sexos entre dois países.

${ }^{23}$ Caritas/Migrantes, 2012, já informada.
Insistimos no fato de que o trabalho nas famílias é o grande espaço para brasileiras, bem como produz situações que poderão resultar em acordos matrimoniais. A realidade de crise econômica na Europa, a necessidade de recomposição de papéis tradicionais no interior das famílias, em termos hierárquicos, de papéis sociais, no cuidado de idosos, crianças e atividades domésticas em geral, entre outros aspectos, faz da possibilidade de uniões conjugais entre brasileiras e italianos uma realidade em evidência.

\section{"Entrei num outro mundo": uniões entre imigrantes e autóctones}

Sabemos que falar em casamentos mistos é, de certa forma, problematizar a noção de diversidade num mundo global, principalmente em razão das técnicas de informação e de conhecimento que temos hoje. O que alimenta essa diversidade? A noção de misto se produz em relação a quê? É o contexto de proveniência? É a família de origem? É a cultura e a etnia? São projetos de vida? É a geografia? Difícil responder; talvez, como forma de saída, possa-se dizer que seja um pouco de tudo isso. Na noção de misto, encontramse presentes aspectos ligados à diferenciação, talvez, até com certo preconceito e estereotipia, distanciamentos em múltiplos âmbitos, mas também possibilidades de agregação e integração, de unidade na presumida diversidade. ${ }^{22}$

Os dados estatísticos na Itália revelam intenso dinamismo nas "uniões mistas" (casamentos) entre imigrantes e autóctones. Para o caso brasileiro, em 2001, o país figurava em terceiro lugar, com 6.133 casamentos entre homens italianos e mulheres brasileiras; em 2008, foram 1.738 casamentos entre italianos com brasileiras, um número menor entre italianas com brasileiros (291 casos); em 2009, as brasileiras estavam em segundo lugar na opção dos casamentos entre autóctones e imigrantes; só perderam para a Romênia, país do Leste Europeu que possui mais de um milhão de imigrantes na ltália. Entre os extracomunitários, as brasileiras estavam (em 2009) em primeiro lugar nessa questão dos casamentos com italianos. Em 2011, $9 \%$ de todos os casamentos mistos foram de brasileiras, passando o país a figurar em $3^{\circ}$ lugar; Lombardia, Vêneto e Lazio são as três regiões de maior concentração de casamentos mistos com brasileiras e, como vimos, são também as regiões de maior presença de imigrantes. Os dados revelam que a idade média de italianos supera os 40 anos e a das mulheres está na faixa dos 30 anos..$^{23}$ Isso está bem presente entre os sete casos brasileiros; há entre eles limites entre idades que vão de até 7 a 19 anos, sempre os homens sendo mais velhos.

Essa realidade de conjugalidade não é nova, mas ganhou intensidade nos últimos anos e chama a atenção 
${ }^{24}$ Segundo o Dossier Caritas/ Migrantes (2012, p. 170), a taxa de divórcio entre os casais mistos, em 2005, esteve em $9,2 \%$; em 2008 em 8,3\%; fatores psicológicos e socioculturais são apontados como fundamentais nesse sentido.

${ }^{25}$ Maurizio AMBROSINI, 2008. de analistas das migrações. É uma interação que permite vincular culturas, espaços físicos, em teoria, diversos; revela certa abertura das sociedades ao horizonte multiétnico, ${ }^{24}$ um laboratório de análise, possibilidade e desafio de convivência entre as diferenças, permite ir além das diversidades étnicas, culturais, de instrução, de condições econômicas, entre outras.

Os matrimônios mistos revelam também vínculos de pertencimentos transnacionais, a "globalização dos processos migratórios", além, é evidente, de possibilidades de alterar costumes, estilos de vida, formas outras de ser pai e mãe, novas expressões relacionais, formas alternativas de integração e que não sejam meramente assimilacionistas por parte das imigrantes. Entendemos que, nesse caso, estão em jogo identidades culturais, tentativas de unir mundos e criar vínculos mais estreitos em horizontes transnacionais. ${ }^{25}$

Não podemos esquecer que também são comuns no país "casamentos arranjados", "casamentos só no papel", "casamento por visto" (obtenção da dupla-cidadania), como ouvimos em pesquisa de campo e no cotidiano das relações com imigrantes. As dificuldades em obter vistos, tanto pelo ius solis (tempo de permanência no país), quanto pelo ius sanguinis (descendência de imigrantes italianos), os estereótipos envolvendo mulheres brasileiras, a legislação "cada vez mais difícil para casar aqui [na ltália] legalmente", a situação nem sempre fácil da vida de imigrante no país, a crise econômica e o aperto do cinto no controle imigratório por parte do Estado, entre outros aspectos, fazem da estratégia dos "casamentos arranjados" um grande expediente junto a imigrantes.

Para os casos de casamentos mistos analisados, na sua grande maioria, os encontros entre os pares aconteceram de uma forma aleatória, "sem querer"; alguns foram mediados por outros e/ou os contatos foram "amadurecendo" no interior das casas, espaço de trabalho de imigrantes. Uma imigrante nos disse que seu pai "já trabalhava pra ele [marido]; eu vim e fui trabalhar na casa dele, né, e, logo que fomos apresentados, alguma coisa surgiu, isso durou dois anos". Um relato de uma imigrante nos dá a ideia da aleatoriedade do primeiro encontro:

Nos encontramos numa churrascaria em Verona, na verdade fui lá pra ver um trabalho de faxineira e, quando cheguei, ele estava sentado esperando ser servido, me viu e pintou algo na hora (risos ao se voltar para o marido). Quando estava saindo, passei próximo à mesa dele e me cumprimentou, ele me convidou se não queria jantar. [...]; sempre até hoje achei que ele tinha outra intenção (olhar irônico do marido)! Fiquei lá com ele. Por horas conversamos. [...]. A história é longa pra 
${ }^{26} \mathrm{Em}$ nosso livro Entre raízes e rotas ..., já informado, encontram-se relatos mais detalhados dessas redes e canais que foram se constituindo e produzindo interconhecimentos que resultaram em uniões conjugais.

27 Domenica SCALERA, 2009.

${ }^{28}$ Adriana PISCITELLI, 2007. te contar, mas muita coisa rolou antes de irmos morar juntos, tive barreiras pra todo o lado, até porque sou 12 anos mais jovem que ele. [...]. Entrei para um outro mundo, tinha mais dúvidas do que certezas, mas depois caiu a ficha e vi que era isso que queria e lutei pra isso. [...]; pensei que quem encara a vida de imigrante já ta vacinada pra esses desafios [...]; faz seis anos que estamos juntos, não casamos, temos um filho de quatro anos que é maravilhoso; é o sentido que dei à minha vida de imigrante; os avós aqui o amam e os meus, então, morrem de ciúmes, vivem pedindo pra deixar um tempo ele lá [no Brasil]. [...]. Aqui é assim, a vida aqui é assim, uma coisa supera a outra, mas tem de ter persistência. (Imigrante, que constitui família com italiano em Verona, entrevistada em outubro de 2011)

Em entrevistas aleatórias com imigrantes brasileiras, vimos que as redes que viabilizam contatos transnacionais, de ações que ligam o Brasil e a ltália, também promovem uniões conjugais. "Primeiro casei no Brasil, tudo direitinho, depois casamos aqui; começamos através de um intercâmbio. Eu vim como enfermeira, e nos encontramos numa festa de brasileiros em Verona", disse-nos uma brasileira, casada há dois anos com italiano e grávida de cinco meses, em outubro de 2011, em Verona. Essa entrevistada disse, ainda, que trabalhou quase um ano na casa do marido, depois saiu e foi para uma outra casa, mas "o namoro seguiu". A imigrante relata que quem conseguiu emprego para ela foi uma entidade que viabilizava intercâmbio como resultado de um acordo de gemellaggio.

Pelas nossas pesquisas, tanto na Itália quanto em alguns locais de maior expressão de saídas (Pato Branco, Criciúma, Caxias do Sul), ${ }^{26}$ ficamos com a impressão de que as redes também auxiliam na busca desses canais alternativos de afetividade; elas permitem abrir portas que podem ter sido secundárias no projeto migratório de indivíduos, podem, inclusive, auxiliar nos matrimônios combinados, nas possibilidades de turismo e de tornar legal imigrantes dentro do país. ${ }^{27}$

Piscitelli ${ }^{28}$ analisa formas de agrupamentos mistos entre imigrantes brasileiras com italianos. Essa autora revela, em suas pesquisas, que muitas dessas mulheres, ao migrarem, já pensavam num projeto de relações sentimentais e conjugais. Diz, ainda, que essas mulheres não desejam se sentir imigrantes, preferem ficar longe dos grupos de imigrantes devido às suas estigmatizações. No caso específico desse tipo de união, a inserção das mulheres brasileiras não depende muito das redes de imigrantes, nem das de auxílio; ainda que muitas das imigrantes analisadas pela autora, no momento da pesquisa, estivessem trabalhando, seus maridos garantiam-Ihes o sustento. Tais mulheres não buscam integrar-

124 Estudos Feministas, Florianópolis, 22(1): 115-133, janeiro-abril/2014 
se na sociedade e nem em meio aos imigrantes brasileiros; porém, estão mais amparadas no campo jurídico, da cidadania e de nacionalidade.

Nos sete casos que acompanhamos, apenas uma declarou que "trabalhou pra isso", ou seja, que já havia emigrado com a intenção também de "casar com um gringo"; as outras enfatizaram que foram processos que aconteceram pela realidade migratória, em geral, do trabalho e de conhecimento previamente existente em razão de acordos de intercâmbios entre regiões, ou seja, fruto de sociabilidades produzidas antes mesmo da emigração. Amizades prévias, contatos no cotidiano do trabalho, em geral, no interior de famílias (compartilhando espaços domésticos e familiares), relacionamentos produzidos pelo horizonte da confiança, das informações e do interconhecimento também foram determinantes para as decisões da conjugalidade oficial.

Nas práticas matrimoniais que analisamos, as diferenças não são percebidas intensamente como limites ou empecilhos, mas como possibilidades e oportunidades de integração, de realização do projeto migratório, de mobilidade social, de "criar filho na Europa", de "continuar vivendo aqui", de "enfrentar esse mundo que já foi muito difícil pra mim". Duas das interlocutoras deixaram clara a existência de dúvidas entre algumas amigas, conterrâneas e mesmo no interior das famílias, sobre as intencionalidades que moveram a decisão de casar, ou seja, se era realmente um casamento movido por amor ou por interesse da duplacidadania, pois "há muito disso aqui, né, então, gente que quer caçar um gringo, ou, então, arranjados entre brasileiros". Uma chegou a nos dizer que "por causa disso é que não foi", pois já era dupla-cidadã ao emigrar.

Ficou claro para nós que os matrimônios mistos demonstram certa redefinição de regras consuetudinárias do campo matrimonial, enfrentamento de resistências por sujeitos considerados estranhos e de fora do quadro de referências idealizado por pais nativos e, em algumas situações, pelos diretamente envolvidos. São mundos que estão em movimento, culturas que podem se ligar a horizontes de mobilidades geográficas, mas também afetividades que transcendem regras sociais e fronteiras geográficas.

Ele ama o Brasil, é só pra ver; acho que casou comigo porque sou brasileira, não é? (voltando-se para ele e rindo); ele tem mais desejo de ir pro Brasil do que eu, por mim eu ficaria aqui, faria uma família aqui. [...]. Temos 17 anos de diferença; como tu disse, italianos casam depois que se dão conta que estão ficando velhos! (olhar de reprovação do marido) [...]. Temos planos de filhos, muitos planos, não é mesmo tesoro? [...]. Foram todos meio contra, até lá em casa; eles lá 
${ }^{29}$ Gaia PERUZZI, 2008.

tinham medo de me perder, mas, depois que ouviram por telefone dele que ele quer morar no Brasil, ficou melhor; aqui sim, foi difícil, não conhecia ninguém da família dele; quando nos encontramos foi numa lancheria no Lago [Lago de Garda], foi um olhar cruzado, como a gente diz. [...]. Moramos juntos. [...]. Sempre trabalhei e quero continuar não dependo dele [...], tenho os pés no chão. [...]. Acho que isso fez meu sogro um pouco mais simpático; disse, na frente de todos, que tenho muitas condições no Brasil, e ele [marido] viu isso, não morremos de fome como muitos pensam aqui na ltália de nós imigrantes e de quem casa com italianos, disse que não queria nada deles; se um dia tivéssemos um filho, seria pra ele, não pra mim. [...]; todas as barreiras possiveis eu enfrentei, nossa mãe! [...]. Graças a Deus, hoje tá tudo mais normal, mas se visitamos pouco. (Imigrante, oriunda de Caxias do Sul RS, que casou com italiano e reside há quatro anos na Província de Bréscia, na Itália)

O protagonismo migratório feminino também se manifesta e atesta nos matrimônios. ${ }^{29}$ Segundo o autor citado, há uma maior presença de mulheres que se casam com homens bem mais velhos, é o caso de brasileiras e mulheres do Leste Europeu (Romênia em particular); há ainda, em razão também disso, muito preconceito em relação à mulher no sentido de estar "se aproveitando da situação". A narrativa abaixo problematiza isso:

Aqui tem muito essa coisa de mulher brasileira como aproveitadora, que quer dar o golpe do baú, como se diz lá [no Brasil], que é puta, que engana os italianos, essas coisas. Eles são todos santinhos e ingênuos, e nós as aproveitadoras. Não é assim, todas as que eu conheço casaram, duas sei que se separaram, mas é menos do que separam no Brasil. A gente enfrenta barreira aqui, até no cartório daqui parece que te olham com desconfiança quando se vai dar os nomes e oficializar. É a ideia que se tem, por isso que a gente enfrenta; é tudo preconceito, de um caso eles fazem cem. Todas as que eu conheço trabalham, se viram, ganham seu dinheiro, investem com os maridos. Eu faço assim; se não der certo amanhã, eu me viro como sempre fiz até agora. [...]. Porque ninguém fala das italianas que casam com brasileiros, então essas querem o quê? (Imigrante brasileira, oriunda de Dois Vizinhos - PR e casada com italiano; há três anos na Itália, estava grávida quando a entrevistamos (novembro de 2011))

A representação existente na ltália de que brasileiras idealizam casar com italianos e que muitas também são prostitutas ou de fácil adesão ao horizonte sexual pode não ser tão verdadeira na prática, mas é exteriorizada em várias circunstâncias, inclusive antes mesmo de emigrarem. Isso 
${ }^{30}$ Análises que criticam essas dimensões podem ser encontradas em BLANCHETTE, 2001; e PISCITELLI, 2008 .

${ }^{31}$ Caterina GOzzOLI e Camillo EGALIA, 2005.

\footnotetext{
${ }^{32}$ Gaia PERUZZI, 2008.
}

produz e baseia relações sociais de múltiplas tonalidades. Assim como inversamente, ou seja, discursos políiticos, de agências internacionais, de governos, tanto de países de saída quanto de chegada, enfatizam o "tráfico de pessoas", o que acaba por estereotipar ainda mais mulheres brasileiras como ingênuas e ignorantes, vítimas indefesas de redes de tráfico, de exploradores e escravizadores de mulheres que emigram sem saber, enganadas por aliciadores e por promessas que se revelam irrealizáveis. ${ }^{30}$ É claro que essa realidade se faz presente, porém, não pode servir para fortalecer o discurso da estereotipia, do colonizador, da generalidade do processo. Há muitos estudos que revelam processos diversos, múltiplos e diferenciados; narrativas ideológicas e culturalistas (tendo nações e grupos étnicos como referência) tendem a corroborar os discursos que fortalecem os controles migratórios por parte de vários países; Espanha, Portugal e Itália tornaram-se expressivos nesse sentido. A questão da prostituição de brasileiras na Itália, bem como aspectos da realidade de "travestis" em cidades como Roma e Milão fazem-se sentir muito corriqueiramente nos jornais. Narrativas preconceituosas são produzidas pelos canais de comunicação, as quais acabam também por gerar ações negativas no âmbito dos controles migratórios e nas representações de brasileiros nesses cenários.

Na prática cotidiana, esses casamentos podem ser sim, como muitos analisam, uma estratégia de enfrentamento dos limites e da discriminação vivida como imigrante, desejo de fazer parte da sociedade, incorporar direitos, desenvolver horizontes afetivos distante do local de origem, aceitar desafios, instrumentalizar uma melhor situação de vida financeira e de obter status social em correspondência e/ou prolongamento do desejo que alimenta o ato de emigrar. ${ }^{31}$ No entanto, essa estrada não tem uma mão só. Para maridos italianos, os universos também são amplos e podem se revelar nos enfrentamentos de oposições no interior da própria família, nas dúvidas e incertezas, na realização de fantasias em torno de representações de sexualidade, curiosidade, atração pelo diferente, diferenciar-se, emancipar-se da dependência da família de origem,$^{32}$ de possibilidade legal de morar no Brasil, como foi evidenciado numa narrativa etc. Intenções subjetivas são difíceis de serem analisadas, de julgamento e análise externa. A narrativa de uma brasileira é significativa nesse sentido:

Morei em Verona mais de 10 anos, conheci ele lá e nunca pensamos em casar, morar juntos, essas coisas; [...] o convite foi dele, não meu; jamais iria morar com a sogra, até porque ela nunca aprovou nosso namoro, nem agora, depois de mais de quatro anos juntos, acho que vai morrer assim [risos ao se voltar para o marido] 
33 Tiziana CAPONIO e Asher COLOMBO, 2005.

${ }^{34}$ Ver também, para o caso de matrimônios mistos nos Estados Unidos, MARGOLIS, 1994.

${ }^{35}$ CAPONIO e COLOMBO, 2005.

${ }^{36}$ Roberto BENEDUCE, 1998.
[...]. Temos uma filha [...]. Ele era rico e eu uma simples e boba imigrante. [...]. Isso deu uma faladeira geral até lá na minha cidade, diziam que eu tinha encontrado o príncipe do dinheiro e que era por isso que tinha vindo pra cá. Na verdade, sempre fui independente, trabalhei e continuo trabalhando. Deixei isso bem claro pra ele, aliás, pra todos; se alguém vai usufruir disso será nossa filha; eu já estou quase me aposentando; ele, pelo que conheço, vai trabalhar até o último dia da vida aqui na Itália no que ele gosta, não viaja, não faz férias; a vida dele é a agricultura, sempre foi. [...] Vivo bem [...]; se voltar um dia será com ele, senão quero morrer aqui [...]. Sou cidadã italiana desde o primeiro dia que pisei na Itália; já fui casada no Brasil e não pretendo morrer sozinha, por isso não posso dizer que não realizei meu sonho. (Brasileira, que constituiu família com italiano numa pequena cidade da província de Verona, oriunda de Maringá - PR)

Autores insistem na noção de "negociação cotidiana" dos processos de diversidade cultural que os casamentos mistos expressam..$^{33}$ A legitimação e o enfrentamento das reações que porventura poderão se constituir, interna e externamente, requerem empenho emotivo e relacional por parte de ambos, enfrentamento da diversidade (a "síndrome de Romeu e Julieta", ou seja, o confronto com o externo, a ideia de que a intensidade da oposição, recusa e contraste reforça a união entre os pares). Autores ${ }^{34}$ insistem que cada situação reserva expectativas e definições das formas de agir, de enfrentar esse novo acordo, que há novas inserções em redes de pertencimento de ambos os cônjuges, bem como estratégias e renúncias no âmbito cultural, principalmente em torno de hábitos e crenças. ${ }^{35}$

A literatura que revisamos sobre o caso italiano enfatiza que as segundas gerações terão mais facilidade nos processos integrativos culturais, étnicos e de nacionalidades; não terão tantos conflitos de identificação, não terão seus pais ainda com forte pertencimento cultural e nem serão tão movidas por preconceitos culturais. ${ }^{36}$ Porém, são realidades em construção e em projeção; vão depender de um conjunto de fatores integrativos, de assimilação, de cidadania social e de convivência intercultural, viabilizados nesse momento e que possam, na prática, alterar o quadro da identidade de imigrantes. No entanto, sabemos que estereótipos, estigmas grupais, redes de tráficos de pessoas, legislações e normatizações de fluxos migratórios, representações em torno da identidade de imigrantes etc. não se alteram tão facilmente assim.

Vimos também, entre os casos analisados de brasileiras que se casam com italianos, que sua identidade laboral não se alterou significativamente; dos sete casos, quatro continuam atuando na esfera doméstica, não mais como depen- 
${ }^{37}$ Foto gentilmente cedida por Ana Carolina em dezembro de 2011
${ }^{38}$ Weber SOARES, 2002; e Soraya R. FLEISCHER, 2002. dentes, mas como esposas, em geral, cuidando da casa e do/a sogro/a; uma esposa continua trabalhando num aviário (produção de frangos), não mais em atividades de trato aos animais, como já vinha fazendo há dois anos junto com seu pai, e sim em atividades de compra de insumos, junto com seu marido; uma continua em sua atividade de vendedora numa banca de frutas, numa cidade próxima de Milão; e uma outra emigrou como enfermeira num acordo de intercâmbio para trabalho (gemellaggio) e continua com trabalhos temporários em clínicas para atendimento de idosos na cidade de Vicenza.

Com isso, percebe-se que a imigração e o imigrante produzem realidades complexas, diversas, difíceis de serem generalizadas; é difícil afirmar que, com os casamentos, imigrantes, ao tornarem-se esposas de italianos e com duplacidadania, alterem drasticamente sua identidade tão logo após o matrimônio. Também é difícil dizer que não possa haver um salto emancipatório e de identidade social delas. $\mathrm{Na}$ realidade, são processos que envolvem situações mais amplas, concepções, representações, políticas públicas, consciência da interculturalidade, integrações sociais em múltiplos âmbitos, sensibilidade social e compreensão de uma realidade que está em profunda mudança.

Imigrantes brasileiros reunidos por ocasião de um jantar e jogo de baralho numa sala adjacente ao pavilhão de criação de frangos na cidade de Quinto, província de Verona. Ao fundo, à direita, há um senhor italiano casado com brasileira que está ao seu lado esquerdo; ambos estavam casados há dois anos, e, quando foi realizada a entrevista, em outubro de 201 1, a esposa estava grávida. ${ }^{37}$

\section{Considerações finais}

Os casamentos mistos vêm se manifestando com intensidade nos últimos anos; são uma realidade bastante recente e tendem a problematizar ainda mais o cenário analítico e cotidiano das migrações na Itália.

A realidade de brasileiras chama a atenção pela questão numérica, mas também por ser uma oportunidade de demonstrar que "há gente com intenção séria que quer dividir os espaços com um italiano, e que não somos todas putane, como se diz por aí", diz-nos uma brasileira, esposa de italiano, em Milão, por ocasião de um jantar em sua casa. Laços e trocas recortam territórios, produzem e/ou fortalecem acordos afetivos, fusionam-se no cotidiano da realidade do imigrante e da imigração; fortalecem-se devido às necessidades, demandas, ausências, distâncias, integração mais intensa e sem preconceitos entre imigrantes e possibilidades afetivas. ${ }^{38}$ 
${ }^{39}$ PISCITELLI, 2007.

Universos afetivos que também demonstram ser dinâmicos e que se expressam nos casamentos mistos envolvem canais constituídos, em geral, no interior do país de destino de imigrantes, os quais interligam microrredes de conacionais com nativos, de amizades, de interconhecimento, de identidades de coirmãos (gemellaggios), de relações no universo do trabalho, em particular no cenário das famílias italianas.

Há redes de dimensões múltiplas, as quais se alteram e se ressignificam no decorrer do tempo. Os agrupamentos familiares e o tempo de permanência no país vão "nos ensinando como se virá; eu mesmo decidi casar e fazer a vida por aqui [...], claro que tive o apoio e a aceitação deles [pais] pra isso", disse-nos uma brasileira que casou em 2010 com italiano na cidade de Bréscia.

O domínio da língua italiana, as experiências no próprio trabalho no interior das famílias, a identidade de mulher e imigrante, o fato de ser brasileira, de comungar aspectos da cultura ocidental e, em particular, italiana, viabilizada pela dupla-cidadania, ou, então, por ser oriundi, entre uma série de outras questões, vão promovendo novas orientações, reconfigurando novos formatos de família, reproduzindo os já conhecidos, vinculando afetivo e contratualmente sujeitos em horizontes transfronteiriços.

Nessa dimensão de ordem afetivo-conjugal, há redes que podem produzir os canais da prostituição, viabilizando mobilidades de pessoas de ambos os países em lugares variados para sua realização. Na ltália, o ramo do mercado do sexo possui uma grande identificação com o Brasil, bem como cidades brasileiras possuem redes que produzem o turismo sexual para estrangeiros, esses, muito identificados com italianos. ${ }^{39} \mathrm{Em}$ cidades maiores como Milão e Roma, essa representação ligada ao mercado do sexo e ao turismo sexual se expressa quase que naturalmente quando se fala em mulheres brasileiras. Porém, há outros horizontes do mercado do sexo, constituídos em instâncias ilegais que envolvem brasileiras em situação de exploração e de grande dificuldade de sair desse cenário em razão das redes bem montadas que são constituídas. É evidente que não dá para fazer uma correlação imediata e apressada, tão comum em discursos de agências internacionais e de governos que buscam imprimir políticas restritivas a imigrantes, entre imigração, prostituição e tráfico de pessoas; isso é muito comum quando se trata de determinados grupos étnicos e de nacionalidades. Essa correlação imediata acaba por (re)produzir preconceitos e estigmas em relação a determinados grupos sociais.

Enfim, dimensões de ordem subjetiva também constroem e alimentam percursos migratórios. Estratégias de inclusão social (ou no espaço de origem ou, então, no de destino), bem como intenções subjetivas, no âmbito dos desejos e satisfações

130 Estudos Feministas, Florianópolis, 22(1): 115-133, janeiro-abril/2014 
${ }^{40}$ Ana Cristina Braga MARTES, 2000 .

${ }^{41}$ CASTLES, 2005. (em particular, expressas na emancipação, qualificação e adaptação, nas interações culturais, afetivas, no status social etc.), ${ }^{40}$ revelam uma dinâmica transnacional, relações que dinamizam, enfrentam e transcendem fronteiras de múltiplos âmbitos e sentidos, contatos e intenções múltiplas, nas quais os atores individuais e coletivos controlam alguns dos processos envolvidos. ${ }^{41}$ Intenções subjetivas se mesclam com outras causalidades; são difíceis de serem apreendidas e exteriorizadas, porém, nem por isso, menos importantes. Os casamentos mistos revelam um pouco disso também.

\section{Referências}

AMBROSINI, Maurizio. Un'altra globalizzazione. La sfida delle migrazioni transnazionali. Bologna: II Mulino, 2008.

ASSIS, Glaucia de Oliveira. "De Criciúma para o mundo: gênero, família e migração”. Revista Campos, v. 3, p. 33-49, 2003.

BAUMAN, Zigmunt. La società individualizzada. Come cambia la nostra esperienza. Bologna: II Mulino, 2002.

BENEDUCE, Roberto. Frontiere dell'identità e della memória. Milano: Franco Angeli, 1998.

BLANCHETTE, Thaddeus, G. "O mito de Maria, uma traficada exemplar: confrontando leituras mitológicas do tráfico com as experiências de migrantes brasileiros, trabalhadores do sexo". REMHU, v. 19, n. 37, p. 79-106, 2011.

BLANCHETTE, Thaddeus; SILVA, Ana Paula da. "'Nossa Senhora da Help': sexo, turismo e deslocamento transnacional em Copacabana". Cadernos Pagu, n. 25, p. 249-280, jul./ dez. 2005

CAPONIO, Tiziana; COLOMBO, Asher. Stranieri in Italia. Migrazioni globali, integrazioni locali. Bologna: II Mulino, 2005.

CARCHEDI, Francesco; MOTTURA, Giovanni; PUGLIESE, Enrico. (a cura di). Il lavoro servile e le nuove schiavitù. Milano: Franco Angeli, 2003.

CARITAS/MIGRANTES. Dossier Statistico 2012. Roma: Fondazione Idos, 2012.

CASTAGNONE Eleonora. Madri migranti. Le migrazioni di cura dalla Romania all'ltalia. Torino: Fieri, 2007.

CASTLES, Stephen. La migration du XXI siècle comme defi à la sociologie. Migrations Société, v. 17. n. 102, p. 19-43, nov./dec. 2005.

DECIMO, Francesca. Quando emigrano le donne. Bologna: II Mulino, 2005.

DECIMO, Francesca; SCIORTINO, Gioseppe. (a cura di). Stranieri in Italia. Reti migranti. Bologna: II Mulino, 2006.

FLEISCHER, Soraya R. Passando a América a limpo. O trabalho de housecleaners brasileiras em Boston, Massachussets. São Paulo: Annablume, 2002. 
FONDAZIONE ISMU. Sedicesimo Rapporto sulle migrazioni 2010. Milano: Franco Angeli, 2011.

GOZZOLI, Caterina; EGALIA, Camillo. Migrazione e famiglia. Percorsi, legami e interventi psicosociali. Bologna: II Mulino, 2005.

HAMMOUCHE, Abdelhafid. Les recomposition cultureles. Sociologie des dynamiques sociale en situation migratoires. Strasburg: PRES, 2007.

KAWAMURA, Lili. Para onde vão os brasileiros? Imigrantes brasileiros no Japão. Campinas: Unicamp, 2003.

LISBOA, Tereza Kleba. Gênero e migrações: trajetórias globais, trajetórias locais de trabalhadores domésticas. Revista Interdisciplinar da Mobilidade Humana, Ano XIV, n. 26/ 27, p. 151-166, 2006.

MARGOLIS, Maxine. Little Brazil: imigrantes brasileiros em Nova York. Campinas: Papirus, 1994.

MARTES, Ana Cristina Braga. Brasileiros nos Estados Unidos: um estudo sobre imigrantes em Massachusetts. São Paulo: Paz e Terra, 2000.

PERUZZI, Gaia. Amori possibili. Le coppie miste nella província italiana. Milano: Franco Angeli, 2008.

. "Mixité sentimentale e comunciazionale tra culture". In: AMBROSINI, M.; BUCCARELLI, F. Ai confini della cittadinanza. Processi migratório e percorsi di integrazione in Toscana. Milano: Franco Angeli, 2009. p. 115-138.

PISCITELLI, Adriana. "Entre as 'máfias' e a 'ajuda': a construção de conhecimento sobre tráfico de pessoas". Cadernos Pagu, n. 31, p. 29-63, jul./dez. 2008.

. "Exotismo e autenticidade: relatos de viajantes à procura de sexo". Cadernos Pagu, Campinas: UNICAMP, v. 19, p. 195-233, 2002.

"Viagens e sexo on-line: a internet na geografia do turismo sexual". Cadernos Pagu, v. 25, p. 281-327, jul./ dez. 2005.

. "Sexo tropical em um país europeu: migração de brasileiras para a ltália no marco do 'turismo sexual' Internacional". Revista Estudos Feministas, v. 15, n. 3, p. 717-774, set./dez. 2007.

SAVOLDI, Adiles. O caminho inverso: a trajetória dos descendentes de imigrantes italianos em busca da dupla cidadania. 1998. Dissertação (Mestrado em Antropologia Social) - Programa de Pós-Graduação em Antropologia Social. UFSC, Florianópolis.

SCALERA, Domenica. "Incontro tra le culture. Le reti migratorie." Revista Interdisciplinar da Mobilidade Humana, v. 17, n. 32, p. 117-132, 2009.

SOARES, Weber. Da metáfora à substância: redes sociais, redes migratórias e migração nacional e internacional

132 Estudos Feministas, Florianópolis, 22(1): 115-133, janeiro-abril/2014 
em Valadares e Ipatinga. Tese (Doutorado em Demografia) - UFMG, 2002.

TEDESCO, João C. Estrangeiros, extracomunitários e transnacionais. Porto Alegre: EdiPUCRS; Passo Fundo: UPF; Chapecó: Argos, 2010. 2012.

Entre raízes e rotas. Passo Fundo: UPF; Itajai: Univali,

[Recebido em 19 de março de 2012, reapresentado em 29 de abril de 2013

e aprovado em 23 de julho de 2013]

\section{Mixed Marriages: New Sociability and Collective Frames. Aspects of the Brazilian Women Immigration in Italy}

Abstract: This paper examines aspects of Brazilian women immigration to Italy with a focus on their marriages to Italian people. It also analizes the labour expectation inside Italian families, as a scenario that allows its possibility. Furthermore, this investigation intends to demonstrate that mixed marriages reveal multiple subjective horizons, discrimination, ethnical social networks, cross-border integrations and family reconfigurations.

Key Words: Integration; Mixed Marriages; Gender. 